\title{
Mechanistic Understanding Leads to Increased Ionization Efficiency and Selectivity in Dielectric Barrier Discharge Ionization Mass Spectrometry - A Case Study with Perfluorinated Compounds
}

Journal Article

Author(s):

Gyr, Luzia; Wolf, Jan-Christoph; Franzke, Joachim; Zenobi, Renato

Publication date:

2018-02-20

Permanent link:

https://doi.org/10.3929/ethz-b-000238127

Rights / license:

In Copyright - Non-Commercial Use Permitted

Originally published in:

Analytical Chemistry 90(4), https://doi.org/10.1021/acs.analchem.7b04711 


\title{
Mechanistic Understanding Leads to Increased Ionization Efficiency and Selectivity in Dielectric Barrier Discharge Ionization Mass Spec- trometry - A Case Study with Perfluorinated Compounds
}

\author{
Luzia Gyr, Jan-Christoph Wolf, Joachim Franzke ${ }^{\dagger}$ and Renato Zenobi* \\ Department of Chemistry and Applied Bioscience, ETH Zurich, CH-8093 Zurich, Switzerland. \\ $\dagger$ Leibniz-Institut für Analytische Wissenschaften - ISAS - e.V., Bunsen-Kirchhoff-Straße 11, 44139 Dortmund, Germany
}

\begin{abstract}
Perfluorinated compounds have unique properties and many practical applications, but are difficult to ionize efficiently with soft ionization methods. An active capillary plasma ionization source based on dielectric barrier discharge ionization (DBDI) coupled with mass spectrometry was used to study the ionization pathway of perfluorinated compounds (PFCs), with the aim of both increasing the ionization efficiency and influencing the selectivity for generating product ions in negative ion mode. Cyclic and linear perfluorinated alkanes were found to mainly form $[\mathrm{M}-\mathrm{F}]^{-}$and $[\mathrm{M}-\mathrm{F}+\mathrm{O}]^{-}$ions, respectively; the $[\mathrm{M}]^{-}{ }^{-}$ion was only obtained at low discharge voltage. Additionally, fluorine attachment $[\mathrm{M}+\mathrm{F}]^{-}$was observed mostly for perfluorinated alkenes. An isotope labeling experiment with ${ }^{18} \mathrm{O}_{2}$ showed that the primary source of oxygen in the substitution reaction is molecular oxygen, reacting with the analyte in the form of $\mathrm{O}^{-\bullet}$ ions. The abundance of $[\mathrm{M}-\mathrm{F}+\mathrm{O}]^{-}$ions can thus be enhanced by increasing the plasma voltage to produce a higher $\mathrm{O}^{-*}$ ion density. The loss of the fluorine (without substitution by oxygen) was mainly observed at high frequency, a fact which can be exploited for tuning the ionization towards specific product ions. Overall, the mechanistic understanding of the ionization of PFCs allowed to increase the selectivity of the product ions, resulting in increased ionization efficiency.
\end{abstract}

In the last decade, plasma-based ionization coupled with mass spectrometry had generated significant interest, as it opens new ways for direct, fast and sensitive mass spectrometric detection of solid, liquid or gaseous samples ${ }^{1-5}$. In dielectric barrier discharge ionization (DBDI), a plasma is generated between two electrodes separated by a dielectric barrier. It was first coupled to a mass spectrometer by $\mathrm{Na}$ et al. in 2007 for the detection of amino acids $^{6}$. Although many applications of plasma-based ionization have been published, fundamental studies are still rare. Such studies are important to improve the technique, especially to enhance the selectivity and the sensitivity for different classes of analytes.

In plasma-based ionization, reagent ions such as $\mathrm{N}_{2}^{+\bullet}, \mathrm{O}_{2}^{+\bullet}$ or $\mathrm{NO}_{3}^{-},{ }^{7}$ are mostly responsible for the eventual ionization of the analyte via charge transfer reactions. The reagent ion $\mathrm{N}_{2}^{+\bullet}$ is formed irrespective of the initial ionization process and independent of the discharge gas, mostly either via Penning ionization ${ }^{8}$ or electron ionization ${ }^{9}$. The processes leading to analyte ions are complicated and affected by many parameters such as the proton affinity and ionization energy of the analyte and also the polarity of the discharge gas. In positive ion mode, protonated analyte $[\mathrm{M}+\mathrm{H}]^{+}$and/or the radical cation $[\mathrm{M}]^{+\bullet}$ are predominantly formed, either through water clusters ${ }^{10}$ or via a radical mediated pathway $^{11}$. The selectivity for the generation of these two ions as well as the overall ionization efficiency can be influenced by tuning the plasma operating parameters, as shown by Badal et al ${ }^{12}$ for the case of flowing atmospheric pressure afterglow (FAPA) ionization.

In negative ion mode, a larger variety of product ions is often observed, including the radical anion $[\mathrm{M}]^{-*}$, the deprotonated molecule $[\mathrm{M}-\mathrm{H}]^{-}$, an anion attached molecule $[\mathrm{M}+\mathrm{X}]^{-}$and oxidized species such as $[\mathrm{M}-\mathrm{X}+\mathrm{O}]^{-13-15}$. Anion production is domi- nant for halogenated, acidic, and nitrated analytes. Different studies have shown that the ionization mechanism in atmospheric pressure chemical ionization (APCI) and direct analysis in real time (DART) is similar to that in atmospheric pressure photoionization (APPI) ${ }^{14-18}$. Therefore, the proposed ionization pathway for negative APPI suggested in the literature can be adapted to dielectric barrier discharge ionization. The radical anion might be formed either through electron capture (1) if the electron affinity of the analyte is positive, or through charge transfer $(2)^{14}$.

$\mathrm{M}+\mathrm{e}^{-} \rightarrow \mathrm{M}^{-}$

$\mathrm{M}+\mathrm{O}_{2}^{-\bullet} \rightarrow \mathrm{M}^{-\bullet}+\mathrm{O}_{2}$

Proton abstraction can occur via the superoxide anion (3) or via the solvent (4), if the gas-phase acidity $\left(\Delta_{\text {acid }} G\right)$ of the analyte is lower than that of $\mathrm{HO}_{2}{ }^{-}$or that of the solvent, respectively. The third proposed pathway is via dissociative electron capture (5) of the radical anion if the gas-phase basicity of the analyte is lower than that of the hydrogen radical ${ }^{15}$.

$\mathrm{M}+\mathrm{O}_{2}{ }^{-\bullet} \rightarrow[\mathrm{M}-\mathrm{H}]^{-}+\mathrm{HO}_{2}{ }^{\bullet}$

$\mathrm{M}+[\text { Solvent-H }]^{-} \rightarrow[\mathrm{M}-\mathrm{H}]^{-}+$Solvent

$\mathrm{M}^{-\bullet} \rightarrow[\mathrm{M}-\mathrm{H}]^{-}+\mathrm{H}^{\bullet}$

Anion attachment (6) is also feasible in plasma chemistry ${ }^{18}$.

$\mathrm{M}+\mathrm{X}^{-} \rightarrow[\mathrm{M}+\mathrm{X}]^{-} \quad \mathrm{X}=\mathrm{Cl}, \mathrm{Br}, \mathrm{I}$

Substitution of a hydrogen, halogen or nitryl group with oxygen ( 7 or 8 ) was also proposed by reaction with the superoxide ion ${ }^{15}$ or with atomic oxygen ${ }^{19}$.

$\mathrm{M}+\mathrm{O}_{2}{ }^{-\bullet} \rightarrow[\mathrm{M}-\mathrm{X}+\mathrm{O}]^{-}+\mathrm{XO}{ }^{\bullet} \mathrm{X}=\mathrm{H}, \mathrm{F}, \mathrm{Cl}, \mathrm{Br}, \mathrm{NO}_{2}$

$\mathrm{M}+\mathrm{O}^{-\bullet} \rightarrow[\mathrm{M}-\mathrm{X}+\mathrm{O}]^{-}+\mathrm{X}^{\cdot} \quad \mathrm{X}=\mathrm{F}$ 
However, the properties of an analyte are not always known, and it is still unclear which reaction occurs under what plasma conditions, since the properties of the plasma also affect the generation of reagent ions, which are in the end responsible for the gas-phase reactions.

Perfluorinated compounds (PFCs) are an excellent test case for studying the variety of the generated product ions in negative mode. PFCs are known to mainly form three product ions: $[\mathrm{M}]^{*}$, $[\mathrm{M}-\mathrm{F}]^{-}$or $[\mathrm{M}-\mathrm{F}+\mathrm{O}]^{-}$. Although the radical anion $[\mathrm{M}]^{-*}$ is also formed in APCI and APPI, the additional ions were different: loss of fluorine was obtained by $\mathrm{APPI}^{20}$ and the substitution reaction of fluorine with oxygen by $\mathrm{APCI}^{21}$ and by $\mathrm{DBDI}^{22}$. PFCs are not only an interesting class of analytes for studying the ionization pathway, they are also used for many applications due to their unique properties and have a significant environmental impact ${ }^{23-}$ ${ }^{25}$. In this study, experiments were carried out to determine the ionization pathway for PFCs and to understand the effect of different plasma parameters, such as voltage, frequency, discharge gas and humidity on the ionization of PFCs. Our ultimate goal is to improve the selectivity and sensitivity in ambient ionization of PFCs based on a better understanding of the ion formation mechanisms.

\section{EXPERIMENTAL SECTION}

\section{Chemicals and Gases}

Perfluorohexane (99\%), isotope labeled oxygen $\left({ }^{18} \mathrm{O}_{2}, 97 \%\right)$ and isotope labeled water $\left(\mathrm{H}_{2}{ }^{18} \mathrm{O}, 97 \%\right)$ were purchased from Aldrich Fine Chemicals (Buchs, Switzerland). Perfluoroheptane (98\%) was obtained from ABCRchemicals (Karlsruhe, Germany). Perfluorooctane (99\%), perfluoro(2-methyl)pent-2-ene (99\%) and perfluoro-2-methylpent-2-ene (99\%) were purchased from Apollo Scientific Ltd. (Stockport, England). Perfluoro-1, 3-dimethyl cyclohexane was purchased from Fluorochem Ltd. (Glossop, UK). Perfluoroprop-1-ene was purchased from PCR Research Chemicals Inc. (Gainseville, USA) and perfluoro-2,3bis(trifluoromethyl)-2-butene was donated by the Chemical Synthesis and Analysis Service from the Laboratory of Physical Chemistry (ETH Zurich, Switzerland).

\section{Vaporization System}

A pressure-assisted vaporization setup was used to generate defined gas-phase analyte concentrations. A detailed description has already been given elsewhere ${ }^{26}$. Briefly, the vaporization system contained a pressurized sample reservoir ( 0.9 bar), which was connected via a fused silica capillary (ID $40 \mu \mathrm{m}$, OD $363 \mu \mathrm{m}$, length $30 \mathrm{~cm})$ to a hollow heating cartridge $\left(200{ }^{\circ} \mathrm{C}\right)$. The sample flowing out of the capillary was evaporated within the cartridge, and a preheated gas stream $\left(\mathrm{N}_{2}, 2 \mathrm{~L} / \mathrm{min}\right)$ was used to transport the sample to the plasma source. The gas flow was set with a mass flow controller (EL-FLOW® Select Mass Flow Controllers, Bronkhorst, Reinach, Switzerland). The gas-phase concentration of the analyte was calculated with the Hagen-Poiseuille equation as reported by Wolf et $\mathrm{al}^{26}$.

\section{Active Capillary Plasma Ionization}

The active capillary plasma ionization source was used to ionize the analytes. ${ }^{26,27}$ It contained a stainless-steel capillary inserted into a glass capillary working as one electrode (ground) and a copper ring surrounding the glass capillary functioning as the counter electrode. The electrodes have a horizontal overlap of 1 $\mathrm{mm}$. A sine-modulated high voltage of $2-6 \mathrm{kV}_{\mathrm{pp}}$ and $6.3-51.5$ $\mathrm{kHz}$ was applied. Nitrogen (purity N4.5), air (N4.5) or pure oxygen (N5.0) were used as discharge gases. The ionization source was directly connected to the mass spectrometer (MS) inlet capil- lary. A schematic of the plasma source and the connection to the mass spectrometer is shown in Figure 1.

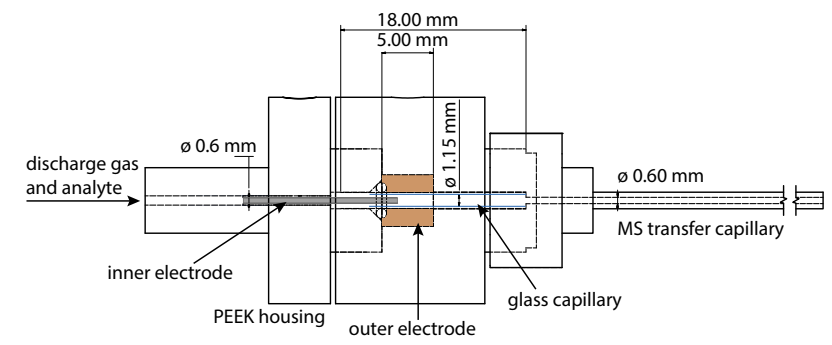

Figure 1. Schematic of the cross section of the active capillary plasma ionization source with the transfer capillary to the mass spectrometer.

\section{Mass Spectrometry}

Mass spectra were acquired in negative ion mode, either with an LTQ ion trap MS or an LTQ-Orbitrap MS (both from Thermo Fischer Scientific, San Jose, USA). The inlet capillary of the MS (ID: $0.6 \mathrm{~mm}$ ) was replaced with a stainless-steel capillary (ID: 0.6 $\mathrm{mm}$ ) connected to an adapter for the active capillary plasma ionization source. The same flow rate $(1.2 \mathrm{~L} / \mathrm{min})$ through the inlet capillary as with the original capillary was achieved. The inlet capillary was heated to $220^{\circ} \mathrm{C}$. Mass spectra were acquired using 3 microscans and a maximum injection time of $100 \mathrm{~ms}$. The mass to charge range was $50-1800$ for the Orbitrap measurements and $50-500$ for the ion trap measurements. The MSMS experiments were performed by collision-induced dissociation (CID) on the Orbitrap (normalized collision energy was set between 35 and 50).

\section{Introduction of ${ }^{18} \mathrm{O}_{2}$ and $\mathrm{H}_{2}{ }^{18} \mathrm{O}$}

Experiments with isotope labeled oxygen were carried out as described above, except that the discharge gas (nitrogen) was spiked with isotope labeled oxygen $\left({ }^{18} \mathrm{O}_{2}\right)$. Both gas flows were controlled by a mass flow controller (EL-FLOW® Select Mass Flow Controllers, Bronkorst, Reinach, Switzerland) to achieve a ratio of $5 \%(\mathrm{vol} / \mathrm{vol}){ }^{18} \mathrm{O}_{2}$ in $\mathrm{N}_{2}$. Isotope labeled water $\left(\mathrm{H}_{2}{ }^{18} \mathrm{O}\right)$ was introduced directly into the heating cartridge via a fused silica capillary (ID $40 \mu \mathrm{m}$, OD $363 \mu \mathrm{m}$, length $55.5 \mathrm{~cm}$ ). The flow was controlled with a syringe and set to a flow rate of $5 \mu \mathrm{L} / \mathrm{min}$. A concentration of $3.5 \mathrm{ppm}(\mathrm{g} / \mathrm{g}) \mathrm{H}_{2}{ }^{18} \mathrm{O}$ in nitrogen gas was obtained.

\section{Data Analysis}

The RAW-files from the mass spectrometer were converted to the mzXML format using msconvert from the ProteoWizard tools and processed further with MATLAB R2016a (The MatWorks, Inc., Natick, USA).

\section{Safety Consideration}

To avoid electric discharge, careful operation of the high voltage power supply is required.

\section{RESULTS AND DISCUSSION}

\section{Ionization Products of PFCs}

Different kinds of perfluorinated compounds were ionized with the active capillary plasma ionization source to demonstrate, among other things, its capability to ionize fully fluorinated carbons. Three types of perfluorinated carbon were measured: linear alkanes (perfluorohexane, perfluoroheptane, perfluorooctane), 
cyclic alkanes (perfluorodecalin, perfluorodimethylcyclohexane) and linear alkenes (perfluoro-2-methylpent-2-ene, perfluoro-2,3bis(trifluoromethyl)-2-butene, perfluoro-prop-1-ene). The structures of the measured compounds are shown in Figure 2.
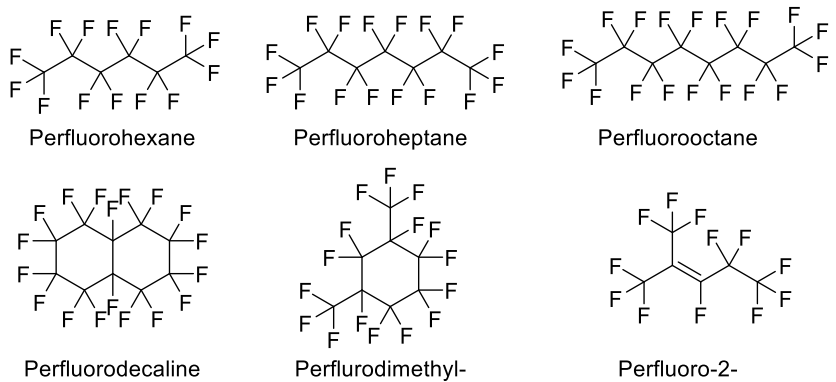
Perflurodimethyl-
cyclohexane

Perfluorodecaline<smiles>FC(F)(F)C(=C(C(F)(F)F)C(F)(F)F)C(F)(F)F</smiles><smiles>FC(F)=C(F)C(F)(F)F</smiles>

Perfluoro-2,3bis(trifluoromethyl)2-butene

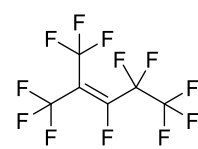

Perfluoro-2methylpent-2-ene

Figure 2. The chemical structures of the measured perfluorinated compounds (PFCs).

The linear and cyclic perfluorinated alkanes yielded [M-3] ${ }^{-}$and $[\mathrm{M}-19]^{-}$product ions, corresponding to $[\mathrm{M}-\mathrm{F}+\mathrm{O}]^{-}$and $[\mathrm{M}-\mathrm{F}]^{-}$, respectively. Additionally, $[\mathrm{M}]^{-*}$ ions were observed for the linear perfluorinated alkanes at low plasma voltage, which will be discussed below. The identity of all product ions was confirmed by high-resolution mass spectrometry and MSMS experiments. The measured $\mathrm{m} / \mathrm{z}$ values of the product ions and the difference to the calculated masses are listed in Table 1. As an example, the mass spectrum of perfluorohexane is shown in Figure 3. The $[\mathrm{M}]^{-*}$ ion is absent. The fragmentation of $\mathrm{m} / \mathrm{z} 318.9803$ ([M-F]') leads to $\mathrm{m} / \mathrm{z} 268.9835\left(\mathrm{C}_{5} \mathrm{~F}_{11}{ }^{-}\right), 168.9900\left(\mathrm{C}_{3} \mathrm{~F}_{7}{ }^{-}\right)$and $118.9927\left(\mathrm{C}_{2} \mathrm{~F}_{5}{ }^{-}\right)$ ions (Figure $3 \mathrm{~b}$ ). The other product ion $\mathrm{m} / \mathrm{z} 334.9752\left([\mathrm{M}-\mathrm{F}+\mathrm{O}]^{-}\right)$ was fragmented to $\mathrm{m} / \mathrm{z} 218.9866\left(\mathrm{C}_{4} \mathrm{~F}_{9}{ }^{-}\right), 168.9897\left(\mathrm{C}_{3} \mathrm{~F}_{7}{ }^{-}\right)$, $184.9846\left(\mathrm{C}_{3} \mathrm{~F}_{7} \mathrm{O}^{-}\right), 134.9876\left(\mathrm{C}_{2} \mathrm{~F}_{5} \mathrm{O}^{-}\right)$and $118.9929\left(\mathrm{C}_{2} \mathrm{~F}_{5}{ }^{-}\right)$ (Figure 3c), which allows confident identification of perfluorohexane.

In the literature about other ambient ionization techniques that showed ionization of perfluorinated alkanes, the observed product ions were not consistent. For example, perfluorohexane can also be ionized with APCI, as shown by Marotta et al. ${ }^{21}$. However, only $[\mathrm{M}]^{-*}$ and $[\mathrm{M}-\mathrm{F}+\mathrm{O}]^{-}$product ions under humid air condition were observed. In another study, Song et al. ${ }^{20}$ obtained the anions $[\mathrm{M}]^{-*}$ and $[\mathrm{M}-\mathrm{F}]^{-}$when ionizing cyclic and linear perfluorinated alkanes with APPI or DART. Furthermore, Song et al. obtained $[\mathrm{M}-3 \mathrm{~F}]^{-}$ions by measuring perfluorokerosene (mixture of perfluorinated alkanes) ${ }^{17}$. Linear perfluorinated alkanes were also ionized with DBDI by Schütz et al., resulting in only the [M$\mathrm{F}+\mathrm{O}]^{-}$product ion ${ }^{22}$. In that publication, the plasma was ignited in helium and the plasma jet, which is responsible for the ionization process, is directed into ambient air. The inconsistancy in the product ion distribution of perfluorinated alkanes generated by plasma-based ionization emphasizes the need for a deeper understanding of the ionization pathway, in order to better control the product ions and to prevent further confusion in spectra interpretation. Therefore, in the next section the ionization pathway leading to these product ions using active capillary ionization will be discussed.

Additionally, perfluorinated alkenes were analyzed, since they are thermal degradation products of fluoropolymers and have envi-

ronmental impacts ${ }^{23}$. Ionization of perfluoroprop-1-ene, one of the thermal degradation product of Teflon (PTFE), produced trimers, dimers and monomers with fluorine and/or oxygen attachment: $[3 \mathrm{M}+\mathrm{F}]^{-},[2 \mathrm{M}+\mathrm{F}+\mathrm{O}]^{-},[2 \mathrm{M}+\mathrm{F}]^{-},[2 \mathrm{M}-\mathrm{F}]^{-},[\mathrm{M}+\mathrm{F}+\mathrm{O}]^{-},[\mathrm{M}+\mathrm{F}]^{-}$. It is well known that small molecules tend to polymerize in dielectric barrier discharge ${ }^{28}$. The MSMS experiment of these product ions did not provide any further information about the constitution of the fluorine attachment. Ionization of perfluoro-2-methylpent-2ene generated three product ions: $[\mathrm{M}+\mathrm{F}+\mathrm{O}]^{-},[\mathrm{M}+\mathrm{F}]^{-}$and $[\mathrm{M}-$ $\mathrm{F}+\mathrm{O}]^{-}$. As for the perfluorinated alkanes, the substitution reaction of fluorine by oxygen could be observed for this molecule. The ionization of perfluoro-2,3-bis(trifluoromethyl)-2-butene resulted in $[\mathrm{M}]^{-},\left[\mathrm{M}-\mathrm{CF}_{3}+\mathrm{O}\right]^{-}$and $[\mathrm{M}-\mathrm{F}+\mathrm{O}]^{-}$product ions. These ions were different compared to those obtained for fully fluorinated alkenes, since the double bond is shielded with four $\mathrm{CF}_{3}$ groups. Therefore, the product ions are more similar to the ions from the perfluorinated alkanes.

Table 1 . The measured $\mathrm{m} / \mathrm{z}$ for the product ions of the different perfuorinated compounds. The difference of the measured mass to the calculated mass is listed in ppm.

\begin{tabular}{|c|c|c|c|}
\hline Analyte & $\begin{array}{l}\text { Measured } \\
\text { mass } \\
(\mathrm{m} / \mathrm{z})\end{array}$ & $\begin{array}{l}\text { Difference } \\
\text { to the } \\
\text { calculated } \\
\text { mass } \\
(\mathrm{ppm})\end{array}$ & Product ions \\
\hline Perfluorohexane & $\begin{array}{l}334.9752 \\
318.9803\end{array}$ & $\begin{array}{l}1.4 \\
1.5\end{array}$ & $\begin{array}{l}{[\mathrm{M}-\mathrm{F}+\mathrm{O}]^{-}} \\
{[\mathrm{M}-\mathrm{F}]^{-}}\end{array}$ \\
\hline Perfluoroheptane & $\begin{array}{l}384.9720 \\
368.9772\end{array}$ & $\begin{array}{l}1.2 \\
1.6\end{array}$ & $\begin{array}{l}{[\mathrm{M}-\mathrm{F}+\mathrm{O}]^{-}} \\
{[\mathrm{M}-\mathrm{F}]^{-}}\end{array}$ \\
\hline Perfluorooctane & $\begin{array}{l}434.9688 \\
418.9741\end{array}$ & $\begin{array}{l}1.0 \\
1.6\end{array}$ & $\begin{array}{l}{[\mathrm{M}-\mathrm{F}+\mathrm{O}]^{-}} \\
{[\mathrm{M}-\mathrm{F}]^{-}}\end{array}$ \\
\hline Perfluorodecaline & $\begin{array}{l}458.9690 \\
442.9741\end{array}$ & $\begin{array}{l}1.4 \\
1.5\end{array}$ & $\begin{array}{l}{[\mathrm{M}-\mathrm{F}+\mathrm{O}]^{-}} \\
{[\mathrm{M}-\mathrm{F}]^{-}}\end{array}$ \\
\hline $\begin{array}{l}\text { Perfluorodimethylcy- } \\
\text { clohexane }\end{array}$ & $\begin{array}{l}396.9731 \\
380.9783\end{array}$ & $\begin{array}{l}4.0 \\
4.5\end{array}$ & $\begin{array}{l}{[\mathrm{M}-\mathrm{F}+\mathrm{O}]^{-}} \\
{[\mathrm{M}-\mathrm{F}]^{-}}\end{array}$ \\
\hline $\begin{array}{l}\text { Perfluoro-2- } \\
\text { methylpent-2-ene }\end{array}$ & $\begin{array}{l}334.9749 \\
318.9801 \\
296.9781\end{array}$ & $\begin{array}{l}0.7 \\
0.8 \\
0.5\end{array}$ & $\begin{array}{l}{[\mathrm{M}+\mathrm{F}+\mathrm{O}]^{-}} \\
{[\mathrm{M}+\mathrm{F}]^{-}} \\
{[\mathrm{M}-\mathrm{F}+\mathrm{O}]^{-}}\end{array}$ \\
\hline $\begin{array}{l}\text { Perfluoro-2,3- } \\
\text { bis(trifluoromethyl)- } \\
\text { 2-butene }\end{array}$ & $\begin{array}{l}299.9829 \\
246.9822\end{array}$ & $\begin{array}{l}5.0 \\
4.4\end{array}$ & $\begin{array}{l}{[\mathrm{M}]^{-\bullet}} \\
{\left[\mathrm{M}-\mathrm{CF}_{3}+\mathrm{O}\right]^{-}}\end{array}$ \\
\hline Perfluoroprop-1-ene & $\begin{array}{l}468.9720 \\
334.9759 \\
318.9811 \\
280.9839 \\
184.9850 \\
168.9899\end{array}$ & $\begin{array}{l}3.8 \\
3.5 \\
4.1 \\
3.3 \\
3.8 \\
3.2\end{array}$ & $\begin{array}{l}{[3 \mathrm{M}+\mathrm{F}]^{-}} \\
{[2 \mathrm{M}+\mathrm{F}+\mathrm{O}]^{-}} \\
{[2 \mathrm{M}+\mathrm{F}]^{-}} \\
{[2 \mathrm{M}-\mathrm{F}]^{-}} \\
{[\mathrm{M}+\mathrm{F}+\mathrm{O}]^{-}} \\
{[\mathrm{M}+\mathrm{F}]^{-}}\end{array}$ \\
\hline
\end{tabular}

\section{Ionization Mechanism of the $[\mathrm{M}-\mathrm{F}+\mathrm{O}]^{-}$Ion for Linear Per-} fluorinated Alkanes

A first hint about the ionization mechanism can be gained by analyzing background ions. The dominant ions are $\mathrm{NO}_{3}^{-}, \mathrm{NO}_{2}^{-}$ and $\mathrm{O}_{2}{ }^{-\bullet}$ using air as discharge gas, as shown in the mass spectrum in Figure 4. The reason for the low number of background species is that the active capillary plasma ionization source features precisely controllable gas-phase conditions and a fully enclosed 
ionization volume, which excludes contamination from the environment. These three ions observed could be either reactive species for the ionization (of PFCs) or could compete with the ionization of the analyte. $\mathrm{O}_{2}{ }^{-}$ions have also been shown to be present in APCI and DART background measurements ${ }^{29,30}$ but according to

a)
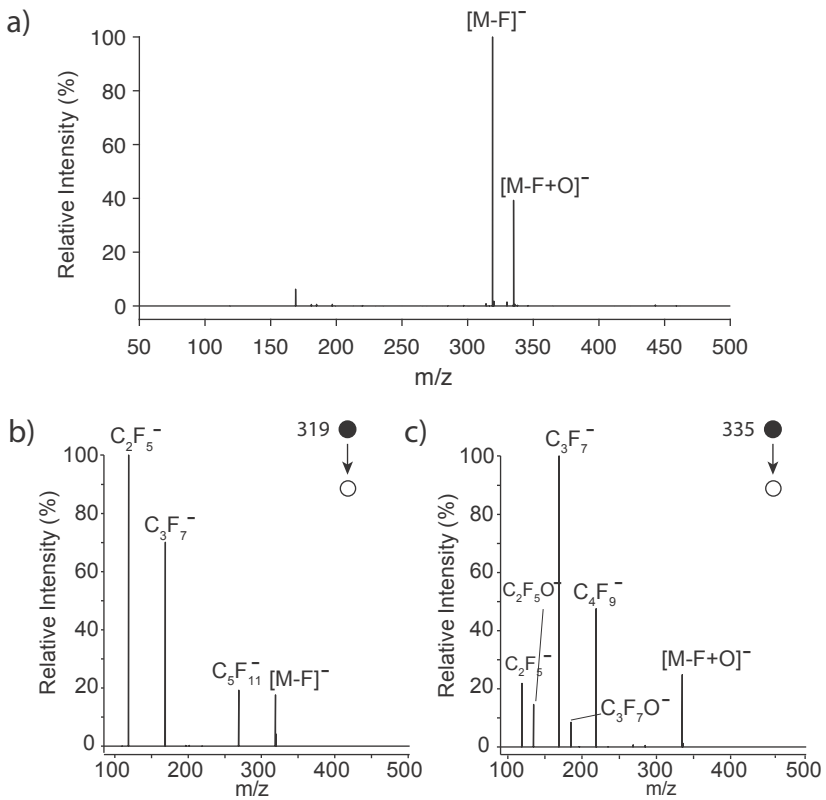

Figure 3. a) High-resolution mass spectrum of perfluorohexane and b) MSMS spectra of the [M-F] product ion and c) MSMS spectra of the $[\mathrm{M}-\mathrm{F}+\mathrm{O}]^{-}$product ion using nitrogen as discharge gas.

a selected ion flow tube (SIFT) experiment ${ }^{19}, \mathrm{O}_{2}{ }^{-\bullet}$ and also $\mathrm{NO}_{3}{ }^{-}$ were unreactive towards PFCs. For the background ions, $\mathrm{NO}_{2}{ }^{-}$and $\mathrm{NO}_{3}{ }^{-}$, the relative abundance of the two nitrogen oxides was increased during injection of PFCs, implying that $\mathrm{NO}_{2}{ }^{-}$and $\mathrm{NO}_{3}{ }^{-}$ are byproducts of the ionization reaction. The supplementary figure $\mathrm{S} 1$ shows the extracted ion chromatogram of $\mathrm{m} / \mathrm{z} 62\left(\mathrm{NO}_{3}{ }^{-}\right.$ ), $\mathrm{m} / \mathrm{z} 335\left([\mathrm{M}-\mathrm{F}+\mathrm{O}]^{-}\right)$and $\mathrm{m} / \mathrm{z} 319\left([\mathrm{M}-\mathrm{F}]^{-}\right.$at injection of perfluorohexane.

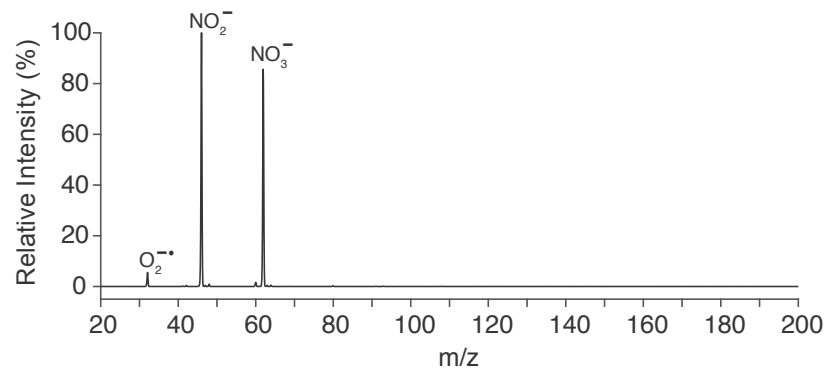

Figure 4. Mass spectrum of the background ions in negative polarity using air as discharge gas.

In order to determine the oxygen source for the $[\mathrm{M}-\mathrm{F}+\mathrm{O}]^{-}$product ions, the discharge gas $\left(\mathrm{N}_{2}\right)$ was spiked with isotope labeled oxygen $\left({ }^{18} \mathrm{O}_{2}, 5 \% \mathrm{vol} / \mathrm{vol}\right)$. The mass spectrum of perfluorohexane (Figure $5 \mathrm{a}$ ) clearly shows that molecular oxygen was a major source for the substitution reaction: the $\left[\mathrm{M}-\mathrm{F}+{ }^{18} \mathrm{O}\right]^{-}$product ion was nearly five times more abundant than the $\left[\mathrm{M}-\mathrm{F}+{ }^{16} \mathrm{O}\right]^{-}$ion. The mass spectra for perfluoroheptane and perfluorooctane showed similar changes upon labeling (Figure S2). However, it is still unclear in which reactive form oxygen reacts with the PFCs.
The reactive species could for example be $\mathrm{O}^{-\bullet}$ or $\mathrm{O}_{3}{ }^{-*}$, since these ions are well known in dielectric barrier discharge ionization $^{31,13,32}$. The SIFT experiment by Morris et al. showed that $\mathrm{O}^{-}$reacted with perfluorohexane leading to $[\mathrm{M}-\mathrm{F}+\mathrm{O}]^{-}$ions ${ }^{19}$, suggesting that $\mathrm{O}^{-\bullet}$ is the reactive species in active capillary plasma a)

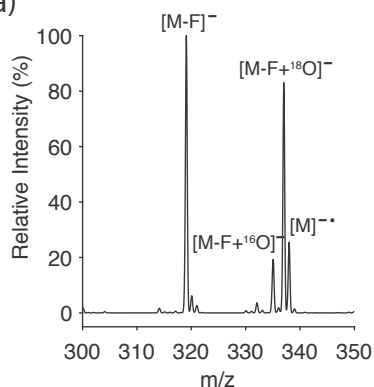
ionization,

b)

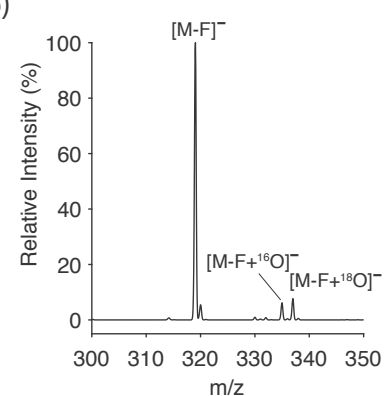

Figure 5. Mass spectrum of perfluorohexane a) using $5 \%$ ( vol/vol) isotope labeled oxygen $\left({ }^{18} \mathrm{O}_{2}\right)$ and b) using isotope labeled water $\left(\mathrm{H}_{2}{ }^{18} \mathrm{O}, 3.5 \mathrm{ppm}\right)$ in nitrogen as discharge gas.

Additionally, the linear perfluorinated alkanes were measured using nitrogen which was humidified with isotope labeled water $\left(\mathrm{H}_{2}{ }^{18} \mathrm{O}, 3.5 \mathrm{ppm} \mathrm{g} / \mathrm{g}\right)$ as discharge gas. It is well known that water plays important roles in the ionization mechanism in positive polarity, such as acting as a proton source and in decreasing of fragmentation ${ }^{11}$. However, the mass spectrum (Figure $5 \mathrm{~b}$ ) showed that under humid conditions the abundance of the $[\mathrm{M}-\mathrm{F}+\mathrm{O}]^{-}$ions were 20 times lower than the [M-F] $]^{-}$ions. The isotope labeled ion $\left[\mathrm{M}-\mathrm{F}+{ }^{18} \mathrm{O}\right]^{-}$showed nearly the same abundance as the unlabeled $\left[\mathrm{M}-\mathrm{F}+{ }^{16} \mathrm{O}\right]^{-}$ions, implying that water is also a source for oxygen in the substitution reaction. A possible reaction could be with $\mathrm{OH}^{*}$, which is formed in dielectric barrier discharge. Repeating the measurements with $100 \%$ water saturated nitrogen led to a decrease of the intensity of all three ions, but the ratio of the different product ions stayed the same. Both molecular oxygen and water are thus important reactants in the substitution reaction leading to $[\mathrm{M}-\mathrm{F}+\mathrm{O}]^{-}$product ion. However, the use of humidified nitrogen led to ion suppression and lower absolute intensities of the product ions.

\section{Increasing the Ionization Efficiency and Selectivity}

As shown above, the $\mathrm{O}^{-}$ion is one of the major reactive species for the substitution reaction, and therefore different ratios of oxygen to nitrogen $(0-100 \%)$ were tried as discharge gas. For the linear and cyclic perfluorinated alkanes, the addition of oxygen to the nitrogen gas lowered the abundance of the two product ions $\left([\mathrm{M}-\mathrm{F}]^{-}\right.$and $\left.[\mathrm{M}-\mathrm{F}+\mathrm{O}]^{-}\right)$, as shown in Figure 6a. This may be explained by oxygen quenching the ionization reaction by producing more $\mathrm{NO}_{3}{ }^{-}$ions, resulting in a lower reaction yield for the perfluorinated alkanes. This result is consistent with the measurements using air as discharge gas instead of nitrogen. For the perfluorinated alkenes however, spiking oxygen to the nitrogen gas did not affect the abundance of $[\mathrm{M}-\mathrm{F}+\mathrm{O}]^{-}$and $[\mathrm{M}-\mathrm{F}]^{-}$product ions. This implies that the perfluorinated alkenes have a different ionization mechanism compared to the perfluorinated alkanes, probably the double bond is affected by photo ionization from the plasma. 
a)

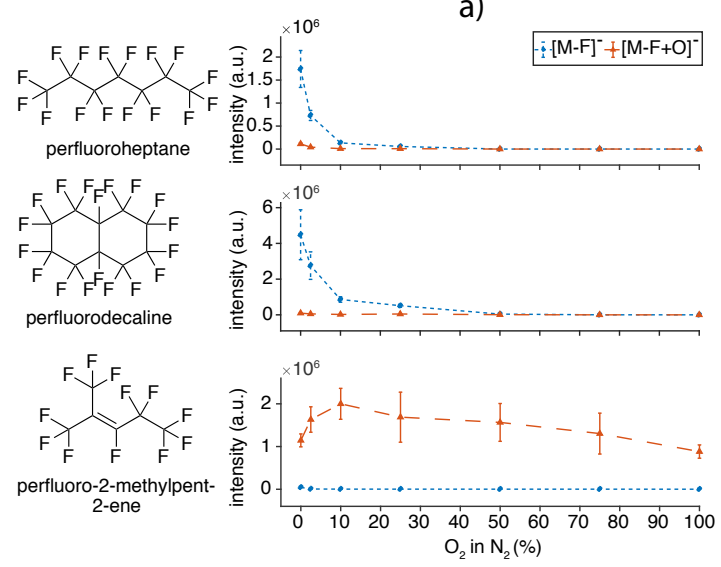

b)
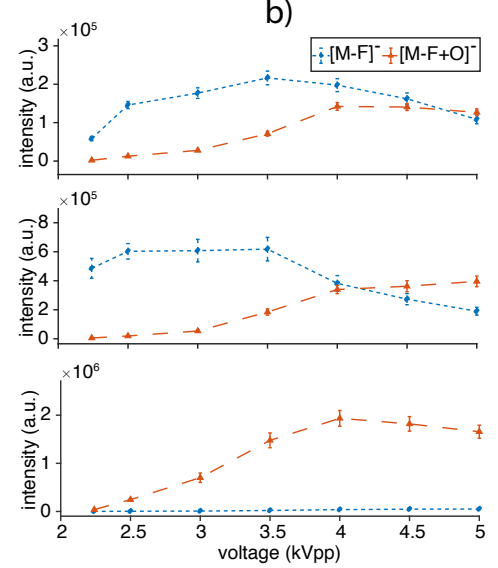

c)
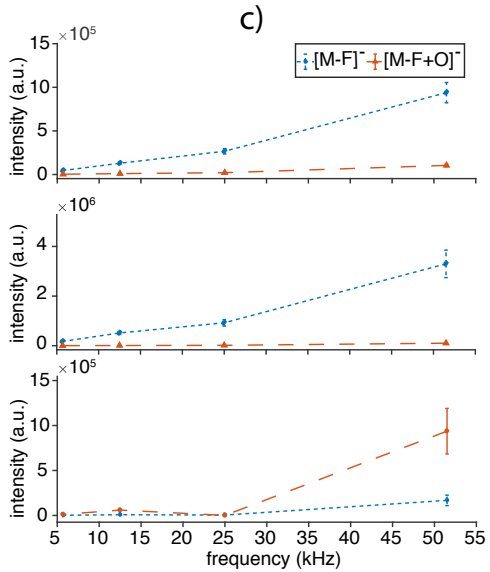

Figure 6. Absolute intensity of perfluoroheptane ions, perfluorodecaline ions and perfluoro-2-methylpent-2-ene ions (rows) at a) different $\mathrm{O}_{2}$ to $\mathrm{N}_{2}$ ratios, $51.5 \mathrm{kHz}$ and $2.3 \mathrm{kV}_{\mathrm{pp}}$, b) different voltages at $12.5 \mathrm{kHz}$ and at c) different frequencies at $2.3 \mathrm{kV}$ (columns). The error bars are the standard deviations of the peak area of the corresponding ion over 100 mass spectra.

An important parameter affecting the ionization efficiency and selectivity of the generated product ions is the applied voltage. The effect of the applied voltage was studied by changing the amplitude of the sine wave. We were able to detect the $[\mathrm{M}]^{-\bullet}$ ion at low voltage (low electron energy), implying an electron capture reaction, as shown in reaction (1). By increasing the plasma voltage to $3.5 \mathrm{kV}_{\mathrm{pp}}$ or $4.0 \mathrm{kV}_{\mathrm{pp}}$, the absolute abundance of the [M-F] and especially of the $[\mathrm{M}-\mathrm{F}+\mathrm{O}]^{-}$ions, respectively, were significantly enhanced. All three classes of perfluorinated molecules showed the same tendency (Figure 6b). The ionization efficiency of $[\mathrm{M}-\mathrm{F}+\mathrm{O}]^{-}$and $[\mathrm{M}-\mathrm{F}]^{-}$product ions was on average increased by around 60 times and 15 times, respectively. The substitution reaction was mostly promoted by high plasma voltage. At 5.0 $\mathrm{kV}_{\mathrm{pp}}$, the $[\mathrm{M}-\mathrm{F}+\mathrm{O}]^{-}$product ion was dominant, but also the fragmentation of the $[\mathrm{M}-\mathrm{F}+\mathrm{O}]^{-}$ion was increased, implying a higher electron energy. The increased abundance of the $[\mathrm{M}-\mathrm{F}]^{-}$product ions was probably due to the increased energy and number of electrons at higher voltage, leading to more cleavage of the fluorine-carbon bond. This is in agreement with the current measurements. Figure 7 a shows the measurements of the current $(5$ repetitions) when applying a sine wave. A current spike represents a discharge event in the plasma, and by integrating the current spikes over a half period, one obtains the charge. The measured charge was increased by increasing the plasma voltage, as shown in Figure 7b.

The applied frequency was another parameter that influenced the ionization efficiency. With increasing frequency, the charge over a half period decreased only slightly, which is shown in Figure $7 \mathrm{~b}$. In other words, the charge per time, i.e. the current, was increased by increasing the frequency. In good agreement with this observation, the abundance of the $[\mathrm{M}-\mathrm{F}]^{-}$ions for the linear and cyclic perfluorinated alkanes, which were mainly generated by reaction with electrons, was significantly enhanced when increasing the frequency from 5.7 to $51.5 \mathrm{kHz}$ at $2.3 \mathrm{kV}_{\mathrm{pp}}$ (Figure $6 \mathrm{c}$ ). The higher frequency promoted formation of $[\mathrm{M}-\mathrm{F}+\mathrm{O}]^{-}$ions for perfluorinated alkenes (Figure 6c), which indicated that there is another reaction pathway responsible for the formation of these ions. So far, frequencies of typically around $20 \mathrm{kHz}$ or even lower are reported in the literature ${ }^{6,22,33}$. However, the present work shows that the use of higher frequencies can increase the ionization efficiency and selectivity in DBDI significantly.
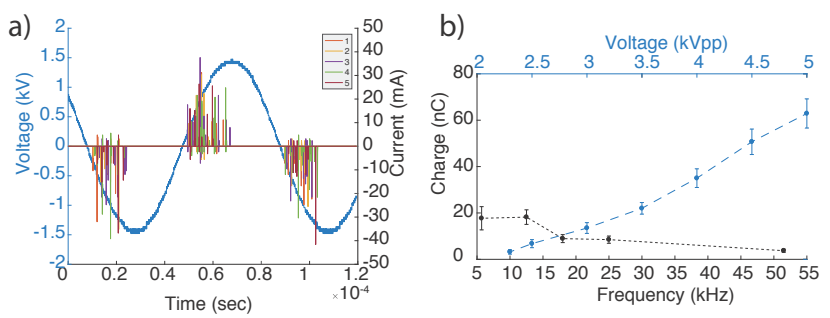

Figure 7 a) The measurements of the current ( 5 repetitions) using a sine wave. b) The generated charge (integrated current) over a half period in the active capillary plasma ionization source at different voltages at $12.5 \mathrm{kHz}$ (blue dashed line) and different frequencies with $2.3 \mathrm{kV}_{\mathrm{pp}}$ (black dotted line). The error bar represents the standard deviation over 100 current measurements.

In summary, the choice of the discharge gas and the electrical parameters are important for the selective and sensitive ionization of PFCs. Generally, for linear and cyclic perfluorinated alkanes high voltage $\left(4 \mathrm{kV}_{\mathrm{pp}}\right)$ led to enhanced abundance of $[\mathrm{M}-\mathrm{F}+\mathrm{O}]^{-}$ ions whereas high frequency $(51.5 \mathrm{kHz})$ led to increased abundance of $[\mathrm{M}-\mathrm{F}]^{-}$ions. The abundance of $[\mathrm{M}-\mathrm{F}+\mathrm{O}]^{-}$for the perfluorinated alkenes can be significantly enhanced by using high voltage and high frequency. With regard to the discharge gas, the best sensitivity could be obtained using pure nitrogen.

\section{CONCLUSIONS}

The active capillary plasma ionization source is capable of ionizing a wide range of perfluorinated compounds. The ionization of perfluorinated alkanes gave a characteristic spectrum of three production ions: $[\mathrm{M}]^{-\bullet},[\mathrm{M}-\mathrm{F}]^{-}$and $[\mathrm{M}-\mathrm{F}+\mathrm{O}]^{-}$. The radical anion and the loss of fluorine were mainly influenced by the reaction with electrons. The energy and number of electrons can be adjusted by the plasma voltage. Therefore, the $[\mathrm{M}]^{-\bullet}$ ion was formed at low voltage (by electron capture) and the $[\mathrm{M}-\mathrm{F}]^{-}$ion was mainly generated at high voltage (electron capture dissociation). The $\mathrm{O}^{-\bullet}$ ion was identified as being responsible for the substitution reaction of fluorine by oxygen. Through the enhanced knowledge about the ionization pathway of perfluorinated alkanes, the selectivity and sensitivity could be improved by increasing the applied frequency, by changing the plasma voltage and by using pure nitrogen as discharge gas. The active capillary plasma ionization 
source has therefore the potential to analyze real samples containing PFCs, such as ski wax, coatings of non-stick cooking-pans, covering of packing material to repel oil, and flame retardants.

\section{ASSOCIATED CONTENT}

\section{Supporting Information}

The Supporting Information as noted in the text is available free of charge on the ACS Publications website.

\section{AUTHOR INFORMATION}

\section{Corresponding Author}

* Prof. Dr. Renato Zenobi, Department of Chemistry and Applied Biosciences, ETH Zurich, CH-8093 Zurich, Switzerland. Email: zenobi@org.chem.ethz.ch

\section{Author Contributions}

\section{ACKNOWLEDGMENTS}

The authors would like to thank Christian Marro from the ETH mechanical workshop for fabrication of the active capillary plasma source and other relevant parts. They thank Heinz Benz for helping with the production and the modification of the electronic for the plasma source. They also thank Daniel Zindel for providing the perfluorinated alkenes and helping with the measurements of them. The authors gratefully acknowledge Dr. Juan Zhang (Novartis AG) for the donation of the LTQ Orbitrap instrument used in this study.

\section{REFERENCES}

(1) Smoluch, M.; Mielczarek, P.; Silberring, J. Mass Spectrom. Rev. 2015, 35, 22-34.

(2) Ding, X.; Duan, Y. Mass Spectrom. Rev. 2013, 34, 449-473.

(3) Guo, C.; Tang, F.; Chen, J.; Wang, X.; Zhang, S.; Zhang, X. Anal. Bioanal. Chem. 2015, 407, 2345-2364.

(4) Brandt, S.; Klute, F. D.; Schütz, A.; Franzke, J. Anal. Chim. Acta 2017, 951, 16-31.

(5) Hiraoka, K.; Ninomiya, S.; Chen, L. C.; Iwama, T.; Mandal, M. K.; Suzuki, H.; Ariyada, O.; Furuya, H.; Takekawa, K. Analyst 2011, 136, 1210.

(6) Na, N.; Zhao, M.; Zhang, S.; Yang, C.; Zhang, X. J. Am. Soc. Mass Spectrom. 2007, 18, 1859-1862.

(7) Venter, A. R.; Douglass, K. a.; Shelley, J. T.; Hasman, G.; Honarvar, E. Anal. Chem. 2014, 86, 233-249.

(8) Olenici-Craciunescu, S. B.; Michels, A.; Meyer, C.; Heming, R.; Tombrink, S.; Vautz, W.; Franzke, J. Spectrochim. Acta - Part B At. Spectrosc. 2009, 64, 1253-1258.

(9) Dzidic, I.; Carroll, D. I.; Stillwell, R. N.; Horning, E. C. Anal. Chem. 1976, 48, 1763-1768.

(10) Cunningham, A. J.; Payzant, J. D.; Kebarle, P. J. Am. Chem. Soc. 1972, 94, 7627-7632.
(11) Wolf, J. C.; Gyr, L.; Mirabelli, M. F.; Schaer, M.; Siegenthaler, P.; Zenobi, R. J. Am. Soc. Mass Spectrom. 2016, 27, 1468-1475.

(12) Badal, S. P.; Michalak, S. D.; Chan, G. C.-Y.; You, Y.; Shelley, J. T. Anal. Chem. 2016, 88, 3494-3503.

(13) Gross, J. H. Anal Bioanal Chem 2014, 406, 63-80.

(14) Kauppila, T. J.; Kotiaho, T.; Kostiainen, R.; Bruins, A. P. J. Am. Soc. Mass Spectrom. 2004, 15, 203-211.

(15) Dousty, F.; O’Brien, R. Rapid Commun. Mass Spectrom. 2015, 29, 1031-1038.

(16) McEwen, C. N.; Larsen, B. S. J. Am. Soc. Mass Spectrom. 2009, 20, 1518-1521.

(17) Song, L.; Dykstra, A. B.; Yao, H.; Bartmess, J. E. J. Am. Soc Mass Spectrom. 2009, 20, 42-50.

(18) Song, L.; Wellman, A. D.; Yao, H.; Bartmess, J. E. J. Am. Soc. Mass Spectrom. 2007, 18, 1789-1798.

(19) Morris, R. A.; Viggiano, A. A.; Arnold, S. T.; Paulson, J. F. Int. J. Mass Spectrom. Ion Process. 1995, 149/150, 287-298.

(20) Song, L.; Wellman, A. D.; Yao, H.; Adcock, J. Rapid Commun. Mass Spectrom. 2007, 21, 1343-1351.

(21) Marotta, E.; Paradisi, C.; Scorrano, G. J. Mass Spectrom. 2004, 39, 791-801.

(22) Schütz, A.; Brandt, S.; Liedtke, S.; Foest, D.; Marggraf, U.; Franzke, J. Anal. Chem. 2015, 87, 11415-11419.

(23) Ellis, D. A.; Mabury, S. A.; Martin, J. W.; Muir, D. C. G. Nature 2001, 412, 321-324.

(24) Begley, T. H.; White, K.; Honigfort, P.; Twaroski, M. L.; Neches, R.; Walker, R. A. Food Addit. Contam. 2005, 22, 10231031.

(25) Scheringer, M.; Strempel, S.; Hukari, S.; Ng, C. A.; Blepp, M.; Hungerbuhler, K. Atmos. Pollut. Res. 2012, 3, 383-391.

(26) Wolf, J.-C.; Schaer, M.; Siegenthaler, P.; Zenobi, R. Anal. Chem. 2015, 87, 723-729.

(27) Nudnova, M. M.; Zhu, L.; Zenobi, R. Rapid Commun. Mass Spectrom. 2012, 26, 1447-1452.

(28) Hubert, J.; Poleunis, C.; Delcorte, a.; Laha, P.; Bossert, J.; Lambeets, S.; Ozkan, a.; Bertrand, P.; Terryn, H.; Reniers, F. Polymer (Guildf). 2013, 54, 4085-4092.

(29) Don, A.; Paradisi, C.; Scorrano, G. Rapid Commun. Mass Spectrom. 1997, 11, 1687-1694.

(30) Cody, R. B.; Laramee, J. A.; Durst, H. D. Anal. Chem. 2005, 77, 2297-2302.

(31) Eliasson, B.; Hirth, M.; Kogelschatz, U. J. Phys. D. Appl. Phys. $\mathbf{1 9 8 7}, 20,1421-1437$.

(32) Ellerweg, D.; Benedikt, J.; von Keudell, A.; Knake, N.; Schulzvon der Gathen, V. New J. Phys. 2010, 12, 1367-2630.

Harper, J. D.; Charipar, N. A.; Mulligan, C. C.; Zhang, X.; Cooks, R. G.; Ouyang, Z. Anal. Chem. 2008, 80, 9097-9104. 
Table of Contents artwork

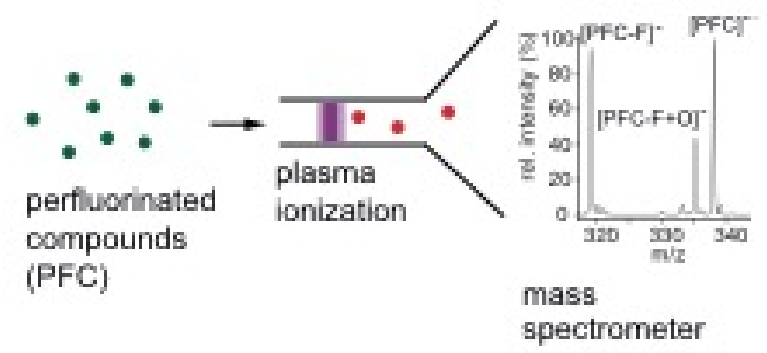

